\title{
The Other Self in Free Fall: Anxiety and Automated Tracking Applications
}

\author{
Christopher Gutierrez ${ }^{1}$ \\ McGill University, Canada
}

\section{doi: 10.5937/comman12-11285}

\begin{abstract}
Recent scholarship on the rise of automated self-tracking has focused on how technologies such as the Fitbit and applications such as Nike+ demand that the user internalize the logic of contemporary surveillance. These studies emphasize the disciplinary structure of self-tracking - noting that these applications rely on logics of selfcontrol, flexibility and quantification to produce particular neoliberal subjects. Following these readings, this paper considers the central role that anxiety plays in motivating, and maintaining, the subject's desire to understand the self through automated tracking systems. I will elaborate on this anxiety in three defined sections. Firstly, I will provide a brief overview of the relationship between anxiety and affect developed in both Freud's and Lacan's work on anxiety. Secondly, I will consider how the particular aesthetic principles of two applications, the Nike+ running application and the Spire breath monitoring application, afford the production of anxious digital selves by drawing on the emerging digital aesthetic of the free-fall in order to create a simultaneous distanciation and conflation of the embodied self and the digital self. Finally, I will consider how self-tracking applications represent a particular affective loop, fuelled by the subject's insatiable jouissance, which drives a never-ending anxious attempt to reunite the subject and object. Ultimately, it is from within these practices of digital self-construction that we can most clearly identify both an everyday anxiety of the self and emergent subjectivity and aesthetic of the present.
\end{abstract}

Keywords: anxiety, affect theory, automation, self-tracking, quantified self, aesthetics

\footnotetext{
1 Contact with author: christopher.gutierrez@mail.mcgill.ca.
} 
'That's not it' is the very cry by which the jouissance obtained is distinguished from the jouissance expected (Lacan, 1998: 111).

\section{Introduction}

The beginning of the Quantified Self movement is commonly attributed to the publication of a widely circulated 2010 editorial by Gary Wolf in The New York Times Magazine. In this article, "The Data-Driven Life", Wolf sets out the general idea for a new form of living guided by the numeric possibilities of emerging tracking applications. These applications, he explains, allow for an increasing quantification of our personal lives as, "Sleep, exercise, sex, food, mood, location, alertness, productivity, even spiritual well-being are being tracked and measured, shared and displayed" (Wolf, 2010). While Wolf was writing prior to the arrival of many of the most popular tracking applications available today, basic tools such as the FitBit, Nike+ and Garmin Running Trackers, and even rudimentary digital pedometers, would all be clear examples of the many technologies of the quantified self. From within this ever-increasing field of tracking applications and personal data, Wolf argues that the Quantified Self movement offers an opening for self-understanding: it transforms the banal everyday into a matrix of information and infographics, and it presents the subject with the visual means to apprehend the self. This chain - from data collection to visual representation - is what ultimately connects many diverse applications within the category of the Quantified Self. As Whitson explains, "The unifying methodology of QS [the Quantified Self] is data collection, followed by visualization of these data and cross referencing, in order to discover correlations and modify behavior" (Whitson, 2014: 346).

There is then a particular gap that is always-already proposed in the Quantified Self movement wherein the subject necessarily separates, and aestheticizes, an image of the self as an object. This gap is clearly articulated as a type of inscription - a movement where the self is written and reproduced as the object of inquiry. The practice of writing the self is not a particularly new one; rather, as Foucault explained, it can be seen in the journaling practices of first and second century Rome (Foucault, 1997: 207). From within these practices it becomes apparent that inscription functions in both the role of the Other for the 
singular subject and as a mode of entry into the depths of the self, as Foucault makes clear how writing reveals "the practice of ascesis as work not just on actions but, more precisely, on thought: the constraint that the presence of others exerts in the domain of conduct, writing will exert in the domain of the inner impulses of the soul" (Foucault, 1997: 208). The space developed through inscription - whether it be created through the self-reflective practice of journaling or through the automated writing of the tracking app - reveals an attempt to distance the self from the self, to transform the subject into an object, and to discipline, and aestheticize, our own selves.

Importantly though, the difference between the journal and the tracking app is a profound one: the application is itself automated and self-producing. Where the journal involves a necessary step back, an ongoing negotiation between the subject and its imagined ideal self that might be best understood as the therapeutic construct of the subject as object, the tracking application does this work of distanciation and evaluation for the subject. In this way, the emergence of the quantified self involves new forms of subject production, new affective regimes of experience and new aesthetics to match our altering sense of ourselves. How, we might ask, does automation rewrite our experiences of therapy? How does affect circulate through automated asocial, and social, networks? ${ }^{2}$ How does it blur the lines between the subject and object? Between the self and other? How does the image of the self emerge when this image is tagged, tracked, circulated and reproduced on different screens? If, as Lacan has made clear in his work on the Mirror Stage, we find the image of our ideal self in the ambient experience of the world and the knowing gazes of the Other, how might these mechanisms be transformed by their digital and automated reconstruction?

It is from within these questions that this paper finds its genesis. Put simply, I argue that what is revealed in the attempts to aestheticize the self through tracking applications is a novel anxious subjectivity of the digital era. If, as Lacan has argued in the recent English translation of his seminar on Anxiety, "There is no auto-analysis, even when one imagines there is. The Other is there" (Lacan, 2014: 22), then much of the power of self-tracking lies in its ability to blur the lines between subject and object, to allow the subject a sense of mastery of the self, and to create the illusion of auto-analysis. Inscription, as the mode

2 For a discussion on the relationship between automaticy and affect theory, see Blackwell, 2014 
through which this sense of division is created, provides a conduit for the production of anxious objects and, rather than quelling the subject's uncertainty, it is in this perceived mastery of the self that anxiety develops further. In this way, the automated tracking application constructs a type of secondary self, a projected digital self that is both the object of anxiety and the object-cause of desire - one and the same in Lacan's reading of anxiety (Lacan, 2014: 40).

\section{Anxiety's Objects, or, Anxiety as Affect}

In order to make sense of the particular contemporary moment, to try and tease out the illusory therapeutic logic of the self-tracking application that is couched in this larger history of writing, separating and mastering the self, it is worthwhile returning to another historic construct that blurs the lines between the self and its other, namely, psychoanalysis' intertwined relationship with anxiety and affect. This relationship begins close to where it will end in this paper, with a declarative uncertainty that, as revealed in Sigmund Freud's "The Problem of Anxiety", explains that, "Anxiety, then, is in the first place something felt. We call it an affective state although we are equally ignorant of what an affect is" (Freud, 1936: 69). For Freud then, anxiety is necessarily affective, but the true meaning of this feeling, and of affects in general, remains almost purposefully unclear. Likewise, Lacan's 1962 seminar on anxiety offers little in the way of a taxonomy or rigid definition of affect and instead presents us with only an explanation of what affect is not: "It is not Being given in its immediacy, nor is it the subject in raw form either. It is in no respect protopathic. My occasional remarks on affect amount to nothing but that" (Lacan, 2014: 14). For Lacan, affect is felt but not experienced by the senses, it is necessarily unknown, and it is not tied clearly to the subject proper. This negative definition is paralleled in his reading of contemporaneous research on affect that he catalogues as being based either on analogy or categorization (Lacan, 2014: 19-20). Categorization lumps together varying affects within specific categories whereas analogical research compares the function of affect across different levels of biology, sociality or psychology. Both, he argues, fail to grasp the nature of affect.

Rather than categorizing or comparing, affect is best understood for Lacan as the function of the key in which "The key is the thing that unlocks and, in unlocking, functions." (2014: 21). In his habitually paradoxical language here, Lacan's argument is quite simply that affect reinforces itself by being generative; 
affect is both a cause and effect, it circulates and regenerates through its circulation. As such, Lacan understands affect as less specific, and more atmospheric, than categorical or analogical research would allow. Affect is something both within and without the subject; it is, he argues, “...unfastened, it drifts about. It can be found displaced, maddened, inverted, or metabolized, but it isn't repressed" (2014: 14). Here Lacan is in agreement with much contemporary work; affect is found in the social, it affects us, it pushes us, it moves bodies and compels motion. ${ }^{3}$ Where he veers off course from much of the current thought on affect, and where the anxiety of affect theory (or anxiety in generally) actually emerges is in affect's relationship with language. As he explains, if affect is unfastened and never repressed, "What are repressed are the signifiers that moor it" (2014: 14). Following Lacan's work on the relationship between language and desire, we see here the emergence of a logic that will run through the remainder of his seminar on anxiety: if affects are unfastened, drifting and atmospheric, and the signifiers that we use to describe them are repressed, and if anxiety is an affect, then we cannot understand anxiety in the words we use to describe it. Rather, we must look to anxiety's objects for a sense of direction.

In his own search for anxiety's peculiar object, Freud's final influential theory of anxiety, from Inhibitions, Symptoms and Anxiety (1926), makes explicit the connection between anxiety and affect. ${ }^{4}$ As an affect, Freud identifies anxiety as a signal and as a response from the ego to danger that produces particular symptoms and inhibitions. Importantly, the danger-situation to which anxiety responds is largely based on early childhood traumas, and for Freud, the helplessness of birth acts as a prototype for anxiety. ${ }^{5}$ The helplessness of being born, of being torn away from the mother and thrown into the air, initiates an undying desire for love in the subject. As Freud explains, "The biological factor of helplessness thus brings into being the first situations of danger and creates the need to be loved which the human being is destined never to renounce" (1926:

\footnotetext{
3 In "Intensities of Feeling: Towards a Spatial Politics of Affect" Thrift outlines four major schools of affect theory - phenomenological/embodied, psychoanalytic, Spinozian/Deleuzian, and Darwinian - all united by the fact that each of them, "depends on a sense of push in the world." (Thrift, 2004: 64).

4 Freud offered two distinct theories of anxiety throughout his work. The first, from 1895, largely identifies anxiety with an accumulation of energy generated from failed sexual experience. The second, from 1921, posits that anxiety is a particular signal for the imminent arrival of a dangerous situation.

5 Freud is both rejecting, and building atop of, Otto Rank's theory that anxiety is based fundamentally on birth. While Freud is sympathetic to this idea, he sees birth not as the initial anxious situation, but rather as prototypical affective state that changes over the life course. See Freud, 1926: 152 for a clear explanation.
} 
99). This desire for love that is initiated alongside a prototype for the anxious moment is ultimately opened up by, not so much the unknown of the world, but the absent. Corporeal, biological and psychic helplessness, all experienced at birth and repeated again and again throughout life, work in tandem with the absent object of desire to meld phobia/desire/anxiety into an inextricable knot. Freud isolates three particular early childhood phobias, "being left alone, being in the dark, and finding a strange person in place of the one in whom the child has confidence (the mother)" (1926: 75), as being key to anxiety, as they replicate this particular feeling of helplessness in tandem with a moment of loss. That is, each of these moments reveals the helplessness that is felt in the loss of the object of desire. ${ }^{6}$ Anxiety then is not just without an object, it is located in the very helplessness of this without-ness, in the very possibility of loss itself.

Anxiety in this reading ultimately produces repression - it pushes back as a type of defence to the danger-situation of loss and represses these original traumas. Thus it works as a signal that invites investigation to locate the root cause of its origins. Lacan's reading of anxiety follows Freud's affective base but eschews Freud's desire to unearth, through language, a solution to anxiety. Rather, Lacan looks towards anxiety's particular inexpressible qualities to further understand the equally inexpressible cause of desire. Here Lacan reverses one of Freud's original ideas. Where Freud defines anxiety in opposition to fear, as it has "... a quality of indefiniteness and lack of object" (Freud, 1895: 100), Lacan declares that anxiety "... is not without an object" (Lacan, 2014: 89). This seemingly simple reversal makes use of a litote, a negation aimed to produce its inverse, to amplify the importance of anxiety's object into something more than a simple object. As Lacan explains:

"This relation of being not without having doesn't mean that one knows which object is involved. When I say, He's not without resources, He's not without cunning, it means, at least for me, that his resources are obscure, his cunning isn't run of the mill." (2014: 89)

\footnotetext{
6 The link between birth, helplessness and desire for the mother is, of course, well established within Freud's psychic universe. The biological role played by the mother in maintaining sustenance is repeated in Freud's psychic economy as a link between anxiety, helplessness and desire that is obviously reminiscent of Irigaray's reading of Heidegger's absent women and air. As Freud writes, "The striking coincidence that both birth anxiety and the anxiety of the infant alike claim separation from the mother as their prerequisite needs no psychological interpretation; it is simply that the mother, who in the beginning had satisfied all the needs of the foetus through her body mechanisms, continues after birth as well to exercise in some measure this same function, although by other means" (Freud, 1926: 77).
} 
To be not without an object reveals the object as something opaque and obscure; the object is there, but unknown and perhaps unknowable. The relationship between anxiety, affect and language is made more clear here as it begins to line up with what Lacan calls the objet petit $a$ - the object-cause of desire. Put simply, for Lacan the object of anxiety and the object of desire are one and the same.

Throughout his seminar on anxiety, Lacan makes clear that the objet petit $a$ is a type of trace, a remainder, from the subject's encounters between the imaginary and symbolic realms (Lacan, 2014: 62-64). Just as the objet petit $a$ is inscribed in the image of the whole self first encountered in the mirror stage an image that Lacan poignantly reminds us is always confirmed by the Other in the infant's quick sideways glance over its shoulder - its transition to the object of anxiety relies on this central location within the self. It is in this movement that the subject looks to the Other for confirmation that we can see the logic and structure of desire and anxiety where, as Lacan explains, “... with this nutating movement of the head, which turns towards the adult as if to call upon his assent, and then back to the image, he seems to be asking the one supporting him, who here represents the big Other, to ratify the value of this image" (Lacan, 2014: 32). Ratifying the value of this image - seeing the whole self and then looking over at the Other to confirm this wholeness - instigates the cycle of desire and anxiety where the objet petit a, this remainder from the imaginary whole self that we can never realize, is displaced and thought to be found in the Other. Desire is transposed onto the Other, when ultimately the objet petit $a$ is in fact the subject. In this way, we are our own objects of desire, our own objects of anxiety, but we look towards the Other for satisfaction. ${ }^{7}$

This chain is an endless one. The object of desire is the impossibly whole self, forever lost when the imaginary realm is drawn into the symbolic and attached to the field of the Other. Anxiety enters into this chain as a different object, one that works:

"By the model of the cut, of the furrow, of the unary train, of the there it is, which in operating always remain tight-lipped - the tight lip or lips of the cut - which become a closed book on the subject, unopened letters sending him off again under closed seal to further traces." (Lacan, 2014: 76).

\footnotetext{
Lacan makes this relationship clear in the final lecture of this seminar, explaining that, "The sole path on which desire can furnish us with that wherein we shall have to recognize our selves as object $a$ - in so far as, at the end-point, an end-point that is doubtless never reached, it is our most radical existence - only opens up by situating the $a$ as such in the field of the Other" (Lacan, 2014: 337).
} 
It is, in this sense, an object that emerges where there should be none. The uncertainty of the object is understood as a type of furrow of still closed lips; it is, as Renata Salecl has made clear, "not the lack, but rather the absence of lack, i.e. the fact that where there is supposed to be lack, some object is present" (Salecl, 2004: 14). The object is an opening in the liminal points of contact with the Other, where we encounter the furrowed lips of the Other and, expecting to see a lack that mirrors our own, we instead encounter a crack in the realm of the symbolic; we encounter something. Anxiety's object becomes overwhelming in these moments precisely because it is a type of potentiality within the world of language where, "Signifiers turn the world into a network of traces in which the transition from one cycle to another is thenceforth possible" (Lacan, 2014: 76).

It is in this position of transition, as the furrow before the opening, as the cleave in the lips that opens to further language, that anxiety's affective role is made clear. As Lacan further argues, anxiety is a type of presentiment, a before that opens up to a coming experience:

"Anxiety is this cut - this clean cut without which the presence of the signifier, its functioning, its furrow in the real, is unthinkable - it's the cut that opens up, affording a view of what now you can hear better, the unexpected, the visit, the piece of news, that which is so well expressed in the term presentiment, which isn't simply to be heard as the premonition of something, but also as the pre-feeling, the pre-sentiment, that which stands prior to the first appearance of a feeling." (2014: 76)

The formula at work here - that anxiety is a type of presentiment, a prefeeling felt before a feeling is known or describable - is clearly drawn from its status as an affect. As an affect, this sense lines up with much contemporary work where, for example, "....affect is what makes feelings feel. It is what determines the intensity (quantity) of a feeling (quality)..." (Shouse, 2005) and it is here that anxiety's radical relationship to affect should be rethought as, what is revealed in the anxious moment is affect's force as a type of predisposition, and further, affect's force as that which structures our approach to an object.

In particular, to return to Lacan's equation of the object of anxiety with the object of desire, it is necessary to remind ourselves that the petit object $a$ is, "... to be conceived of as the cause of desire...the object [that] lies behind desire" (2014: 101). As the object of desire and the object of anxiety are one and the same in Lacan's reading, what is revealed here is that both anxiety and desire are affects that emerge from within the space of the subject, and further, that 
both anxiety and desire are affects that propel us forward into the world. We are pushed forward in pursuit of our desires and we experience anxiety precisely at the moment where we encounter the objects of this desire. ${ }^{8}$ The result is an affective loop, a continuous circle, an unending pursuit of jouissance and of das Ding. ${ }^{9}$ This pursuit is one that necessarily goes unfulfilled, as Adrian Johnstone has made clear:

"The 'jouissance expected' is an illusory, mythicized 'full satisfaction,' namely, the re-finding of das Ding, the decisive final quelling of the incessant clamoring of the drives. However, what the subject always gets (i.e. the 'jouissance obtained') is, at best, a pleasure that falls short of the idealized standard." (Johnston, 2002)

In place of fulfillment, the pursuit of jouissance will always fail to satisfy us. As we approach the petit objet $a$, as we are propelled forward to what we imagine as our ideal selves revealed through the other, we are struck by anxiety. What, we might wonder, would it mean to encounter ourselves? What would it mean to finish the project of the self? In this possibility of lack fulfilled, in the possibility of a lack of lack, we encounter anxiety's object. Like das ding itself, the centrality of anxiety's object is also its very exclusion. ${ }^{10}$ In this way, anxiety is best understood as an affect, as that which guides and directs our approach to our selves and our objects of desire. Just as the satisfaction of jouissance is endlessly deferred for another object, anxiety endlessly defers its own object. Anxiety functions as both an opening and impediment then - it emerges alongside desire to move the subject forward, but it equally emerges as this desire is necessarily impeded and unfulfilled. As we approach ourselves in writing and in language, as we begin to track ourselves and automate our writing, we consistently fail to grasp that whole self and are left anxious and incomplete.

\footnotetext{
${ }^{8}$ A brief note to thank the anonymous reviewer who made this important distinction clear. In as much as the object of desire and the object of anxiety are equated in Lacan's seminar on Anxiety, it is necessary to make explicit the role of jouissance in this relationship as it helps to understand the habitual drive of anxiety and, for my own work, it helps to understand the ongoing repetitions of digital technologies.

9 Lacan introduces his reading of das Ding as a particularly affective object in Seminar VII: The Ethics of Psychoanalysis where he notes that this object is one that functions beyond the signified and is, "characterized by primary affect prior to any repression" (Lacan, 1992: 54). That is, like anxiety's affective relationship, das Ding is necessarily outside of, or before, language. It is an affect prior to significations repression.

${ }^{10}$ This paradoxical situation is made clear by Lacan when he notes of his own diagrams of das Ding, "Simply by writing it on the board and putting das Ding at the center, with the subjective world of the unconscious organized in a series of signifying relations around it, you can see the difficulty of topographical representation. The reason is that das Ding is at the center only in the sense that it is excluded" (Lacan, 1992: 71).
} 


\section{In Free Fall: Self-Tracking and Anxious Aesthetics}

\subsection{Case 1:The Nike+ Running App}

Opening up the Nike+ Running App reveals a specific sociality to selftracking, an Other that is always projected onto the screen alongside the self. The launch screen is a top-down image of a pack of runners moving forward (See Image 1), the home screen gives a cumulative total of your statistics (number of runs, total miles run, Nike fuel consumed) and a list of the recent totals of any other contacts who use the app (See Image 2), and the menu screen fol-

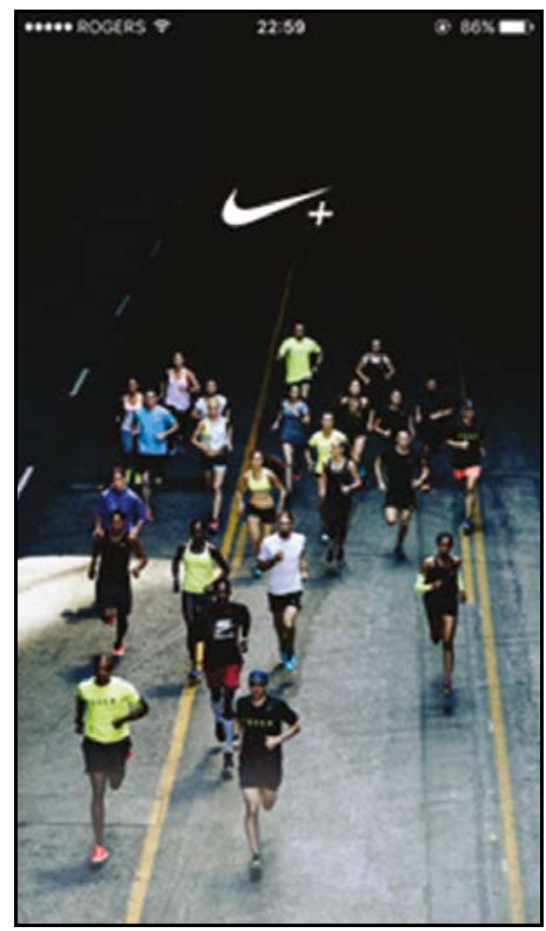

Image 1: Opening Screen of Nike+

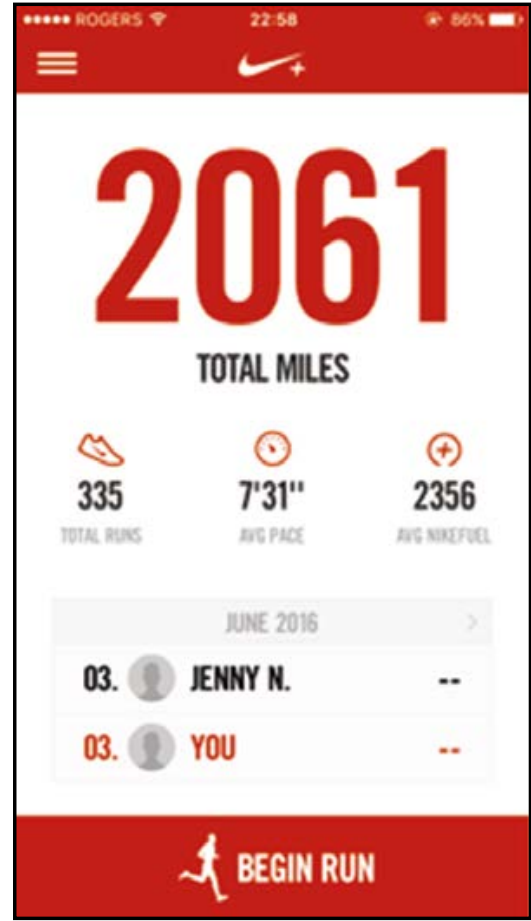

Image 2: Comparison with Other Users 
lowing any run offers a number of ways to share your statistics on social media. ${ }^{11}$ This sociality is both central to, and masked by, the app's tracking functions: by using both the GPS monitors and the accelerometers and gyroscopes built into contemporary smart phones, the app is able to keep a constant record of your movement; it is able to constantly and automatically write your self and to track that self against an Other.

From within the application, a couple of small taps will draw on this self-writing to give further visual details regarding the specifics of each run. Going over my own recent history, I click on a run from May 13th, 2016 and I get to see a map of my route, a reminder of the too-many-miles run in the same old pair of shoes, and a smiley - in this case not quite smiling or frowning - that announces how I felt that day. (See Image 3). Like the launch screen

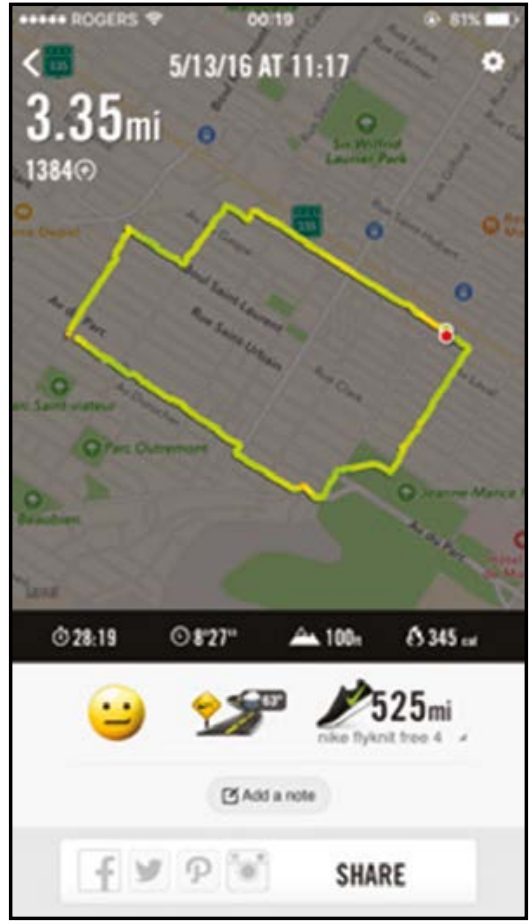

Image 3: Map of Recent Run that opens the app with an image of a pack of runners taken from above, in these visual representations of physical activity the experience is transformed from something corporeal to something topdown and cartographic: the feeling of the street is replaced by the knowledge of the map. In this way, the Nike+ Running app splits the user into two parts: subject and object, user and data, self and other.

In so doing, the app draws on an emergent aesthetic of urbanism and digital space. This aesthetic is not the one defined by De Certeau's (1984) traditional binary of the street and the bird's eye view, but rather it pulls on the surveillance view from nowhere and everywhere, from satellite images and Google maps, and from the amorphous network of images consumed everyday on

\footnotetext{
${ }^{11}$ Within the larger logic of cross-platform synergy, Nike has developed a proprietary energy measuring unit - NikeFuel - to replace calories across its many different applications. Nike fuel works then as a "universal way to measure all kinds of activity - from your morning workout to your big night out" ("What is Nike Fuel?", 2016) that functions and syncs across multiple applications.
} 
smart phones and tablet screens. ${ }^{12}$ This new view and emerging aesthetic is most clearly defined in Hito Steyerl's article "In Free Fall: A Thought Experiment on Vertical Perspective" wherein she follows the rise of new satellite and tracking imagery against the withering horizon of linear perspective to note that, "for many people today the simulated grounds of aerial imagery provide an illusionary tool of orientation in a condition in which horizons have, in fact, been shattered" (Steyerl, 2011). A sense of control and stability is given over to the user in these cartographic moments as they come to mask the fact that, "Time is out of joint and we no longer know whether we are objects or subjects as we spiral down in an imperceptive free fall" (Steyerl, 2011). This logic is clear in the moment when any given run is open on the Nike+ app. The cartographic image begins with a quick animation, a slow rotation and zoom in on the space of the map that mirrors the more familiar animation used by Google maps when a user shifts from street view back to a top down map.

In this way, Nike+ capitalizes on both the free-fall of our contemporary moment and the sense of control given over to surveillant and top-down imaging. On the one hand, the app invites the user to move away from the embodied sensation of running by replicating the slide from the street to the satellite, a slide that has become a familiar sensation in the contemporary moment and thus draws on its users' knowledge and comfort with their own digital selves. On the other hand, the application always necessarily conflates the subjecton-the-screen with the subject-in-the-flesh through a combination of what Alexander Galloway has referred to as the diegetic and non-diegetic aspects of video game action where the diegetic action advances the first-person narrative of the game and the non-diegetic, off the screen action, of the user establishes the conditions of game play (Galloway, 2006: 6-8). Together then, it is in the embodied action of the runner that the narrative of Nike+ unfolds as each physical step taken and mile run allows the application to accumulate numeric values and, simultaneously, with each topographic representation of a previous step the application posits both a stable ground and a stable self over which the user has both distance and mastery.

Thus, the Nike+ application blurs the line between the user and their image, between the self and its object, through a repeated conflation of the physicality of the subject and object alongside a repeated distanciation of these two forms. This repetition of conflation and distanciation of subject and object, of self and

${ }^{12}$ For De Certeau's different views of the city, see De Certeau, 1984: 93-95. 
self-image, is itself mirrored in the affectivity of anxiety in psychoanalysis. Where Freud sees anxiety's affective power located in the potential loss of an object, in the space of without-ness, we can see this anxiety within the separation of the self and its screen-based object. And where Lacan sees anxiety in the very presence of the anxious object, in the space filled by the Other where there should be none, we can see the anxiety produced through the repeated conflation of our digitalself with our embodied self. That is, in the very moment where the application proposes the equivalency of the data produced on the screen and the embodied self, we encounter ourselves on the screen and we encounter the Other, in the form of automated writing that confirms our digital selves, in the data we have produced. The screen becomes a liminal space in this reading - it is the place of contact between two parallel selves and, in the vocabulary of the Mirror Stage, it is both the mirror and the glance over the shoulder. Anxiety emerges precisely in this moment where we expect to find a gap, a lack that is common to the self and the Other, but instead we encounter a confirmation of the relationship between the diegetic and the non-diegetic; we encounter an object, a complete self confirmed in data, where there should be none.

\subsection{Case 2: The Spire Breath}

Equally though, we see this anxiety producing distanciation and conflation of the self repeated in the aesthetic constructions of a multitude of other selftracking applications. The Spire breath tracking application provides perhaps the clearest example of this automated anxiety as it uses a separate monitor to track the non-diegetic breaths of the subject-in-the-flesh for any symptoms of emotional discord in order to advance the diegetic imagery of the subject-onthe-screen. Spire, an application that aims to help its users breathe better in order to "unlock the ability to control our emotions, fears, and keep a clear mind" ("Spire", 2016) works by having the user wear a small monitor that keeps real time statistics of their breathing rates and a log of all of their previous breathing habits (See Image 4). Under Spire's guise, even habitual breathing can become a habit to work on and, when a user begins to speed up their breathing, the application alerts them to their developing corporeal stress and invites a conscious intervention. ${ }^{13}$ In this way, Spire functions as a type of pre-sentiment; as a warning symbol of upcoming anxiety.

\footnotetext{
${ }^{13}$ Habit plays an important role here as the repetition sought by the user of self-tracking applications is, of course, essential to the collection of data for the producers of these applications. For more on the relationship between habit and data, see Chun (2016: 372).
} 


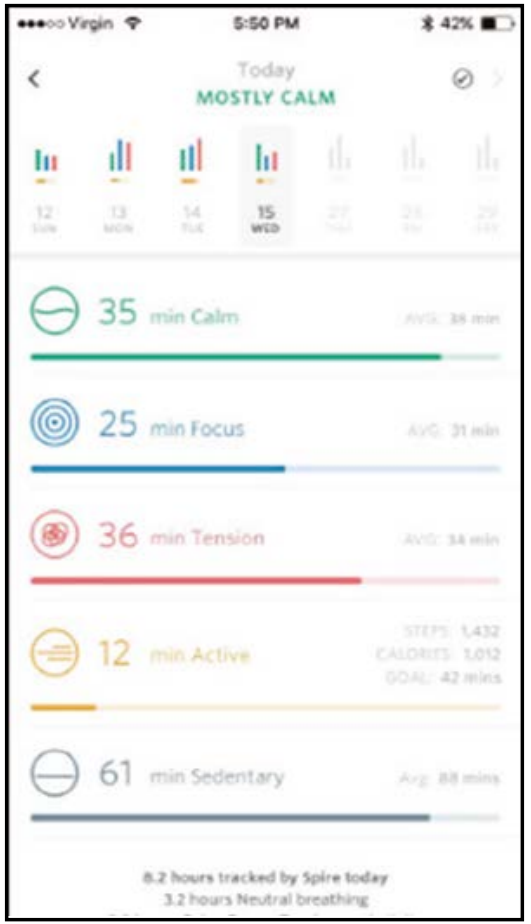

Image 4: Spire Breathing Log
In this space, anxiety takes on a specific form of futurity that mirrors Freud's reading of a central symptom of anxiety, anxious expectation, which he describes in a series of gendered examples:

"A woman, for instance, who suffers from anxious expectation will think of influenzal pneumonia every time her husband coughs when he has a cold, and, in her mind's eye, will see his funeral go past; if, when she is coming towards the house, she sees two people standing by her front door, she cannot avoid thinking that one of her children has fallen out of the window; when she hears the bell ring, it is someone bringing news of a death, and so on - while on all these occasions there has been no particular ground for exaggerating a mere possibility." (Freud, 1926: 92)

Just as Freud's expectant subject invites anxiety through a specific orientation - through a mode of apprehending the world that always opens to a catastrophic future - the Spire breathing app positions anxiety as an expectant state. That is, it posits the body as an alarm for arising anxiety that the subject can ultimately control. Spire's claim to therapeutic power comes from a deeply cognitive understanding of the ability of the mind to control the body then, as their promotional website explains, "Respiration is the only autonomic function you have control over" ("Spire", 2016), and it thus aims to transform anxiety into actionable data for the subject. As anxiety emerges as data the subject is invited to address its habitual nature, to track out the patterns, similarities and geographies of their anxiety and to seize control of these habits.

Curiously though, this cognitivist approach ultimately returns to the affective nature of anxiety. As Freud again makes clear, the slide between objects in 
the moment of anxious expectation, the movement from a cough to influenza and from a doorbell to death, is a transformative one that reveals the atmospheric nature of anxiety; it is, he writes, as if "a quantum of anxiety in a freely floating space is present, which, where there is expectation, controls the choice of ideas and is always ready to link itself with any suitable ideational content" (Freud, 1926: 92). From within this quantum of free-floating anxiety we see that the affective and predictive power of anxiety comes from its role as a pre-sentiment: it emerges prior to its objects, it is an orientation and an approach to the world. Following this, as research into the slide between anxiety and anxiety disorders has routinely shown, there is a clear form of embodiment where the anxious subject is overly aware of their own anxiety and Spire, in its constant system of monitoring and alerting, externalizes and visualizes this anxious orientation as a data set. ${ }^{14}$ Thus, in the logic of the Spire breathing application, the experience of anxiety is predictive as both a data set - it is trackable, monitorable and understood as preventable - and as an affect - it is a looping pre-sentiment that reproduces anxious expectations and anxious orientations.

In order to assure its users that Spire can ultimately interrupt the recurrent anxieties that the application is itself visualizing, Spire relies on a topographic record for the user - it pinpoints the location of an anxious moment and represents that back to the user as a GPS located dot on the map (See Image 5) - to provide a sense of distanciation and objectification from the self. Just as Nike+ relies on blurring the lines between subject and object through both a conflation and distanciation of the two, Spire equally transposes the automaticity of affect and anxiety into the control of cartography. This slide, from the run to the satellite and from the breath to the map, operates like the function of the key in Lacan's reading of anxiety in that it is both in line with the emergent digital aesthetic of self-tracking and is constantly creating and enacting the very mode of aestheticization that has developed in response to these same technologies. In this way, Spire's ability to track the autonomic functions of the body and to transform these functions into a data set that offers the promise of control reveals the anxiety of a broader contemporary moment - it reveals how the habituated and repetitive conflation of the digital and embodied self, the unending movement between subject and object, opens up to a new digital aesthetic marked by a sense of in-betweenness and an ongoing free-fall.

\footnotetext{
${ }^{14}$ As Clark and Beck have made clear, "Individuals prone to panic are oriented toward selectively attending to internal somatic or mental processes... The orienting mode in panic disorder is primed towards rapid detection of interoceptive cues that could represent an immediate and imminent danger to survival” (Clark \& Beck, 2010: 289).
} 


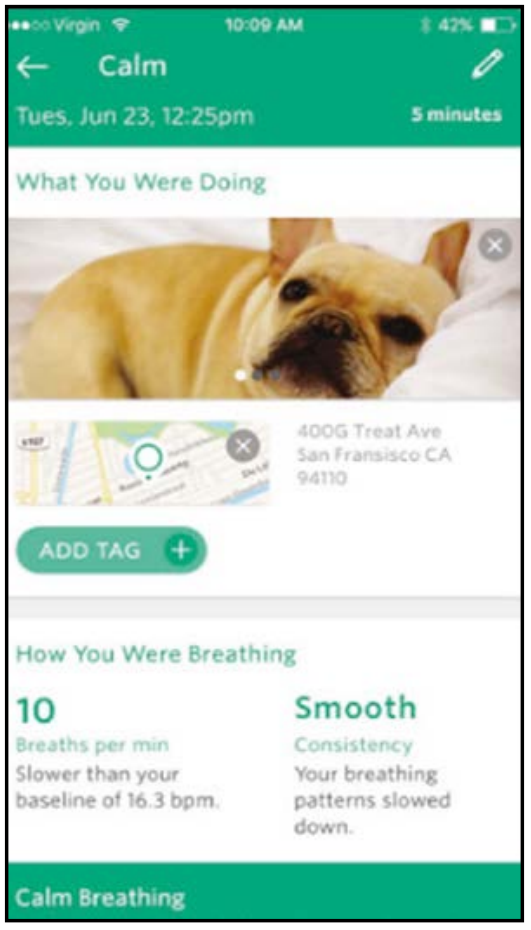

Image 5: Spire GPS Map

The decision to offer satellite visions of anxious moments and miles run offered by both Spire and Nike+ works specifically within this digital aesthetic as it attempts to transform the perpetual sense of movement and free-fall into the uncertain possibility of stability. That is, these applications draw on our growing familiarity and comfort with seeing the world from above to replicate our belief in the stability of the ground and to confirm the stability of the self in the world. Again, as Steyerl has argued, this view functions through the supposition of stability while, in fact, it moves subjectivity away from the ground and into the liminal space of the screen:

“...many of the aerial views, 3D nosedives, Google Maps, and surveillance panoramas do not actually portray a stable ground. Instead, they create a supposition that it exists in the first place. Retroactively, this virtual ground creates a perspective of overview and surveillance for a distanced, superior, spectator safely floating up in the air...This establishes a new visual normality - a new subjectivity folded into surveillance technology and screen-based distraction." (Steyerl, 2011)

The stable ground of Google Maps and surveillance panoramas is less illusion than it is uncertainty here; it is not false, but it is not consistent either. In Steyerl's reading, this emergent digital aesthetic of the free-fall is built on an ever-present anxiety and an ever-present supposition of stability. ${ }^{15}$

\footnotetext{
15 Steyerl presents this particular aesthetic against a longer historical backdrop based around the shift from linear perspective to the perspective of the free-fall. In this way, she is able to present the contemporary moment as one that
} 
In the discursive and aesthetic construction of self-tracking applications this same logic underlies the users' supposition of the self. That is, just as surveillance and mapping applications rely on the uncertain possibility of stable ground, the drive behind the self-tracking application relies on the uncertain possibility of a stable self. As Morozov makes clear:

"Members of the Quantified Self movement may not always state this explicitly, but one hidden hope behind self-tracking is that numbers might eventually reveal some deeper inner truth about who we really are, what we really want, and where we really ought to be. The movement's fundamental assumption is that the numbers can reveal a core and stable self - if only we get the technology right." (Morozov, 2013: 307)

Within the logic of self-tracking, the self is revealed to be an uncertain supposition. There is certainly a belief in its existence, but this belief both fuels and is fuelled by the repetitions of the self-tracking application; it is fuelled by a belief that with the right level of precision we may ultimately capture ourselves on the screen. The desire here is both pragmatic, a question of fitness and wellbeing, and existential, a question of who we really are and what we can be. Both Nike+ and Spire demonstrate the aesthetic connections between these novel forms of self-construction and new mapping and surveillance technologies because, just as the they posit a stable horizon, a ground that the subject could theoretically run and breathe on, they equally posit the possibility of a solid grounded self. In this way, self-tracking applications work through an aestheticization of the self that is necessarily a question of both proximity and distance: by pulling on this new digital aesthetic of the free-fall and the non-space, selftracking applications are able to extract an image from our most embodied experiences - running, sleeping, eating, breathing - in order to offer a potentially malleable, digital version of those experiences.

We are presented then with a paradoxical anxiety: the movement to construct a second self within the field of an emergent digital aesthetic is fuelled by an anxiety to create distance between the self as subject and the self as object, yet it equally maintains an ongoing anxiety by consistently impeding this distanciation, by consistently reminding the user that the digital self and the

is different from the past as the traditional rules and logic that govern linear perspective are revealed to be without grounding. In this way, the present is characterized by a sense of free-fall, a groundlessness, and an uncertainty that is both frightening and potentially liberating. See Steyerl (2011). 
everyday self are somehow one and the same; they are somehow conflated. The diegetic and non-diegetic cannot be pulled apart; the screen is the liminal space between selves - it is simultaneously mirror and Other. Further to this, as Lacan makes clear with regard to the object of anxiety and the object of desire - in this case the anxiety emergent from the desire for the digital self on the screen and the confirmation of that idealized screen self - there is no distance between the self and the object; movement between the two is not possible, "you are $a$, the object, and everyone knows that this is what is intolerable" (Lacan, 2014: 103). In this way, the anxiety behind the desire to distance the subject (the runner, the body) from its object (the digital profile, the satellite) is an anxiety of impediment; it is the moment when "movement is reduced to agitation, a kind of inexpedient-tentative running in place" and when "affect is known by a more specific name; it is called anxiety" (Copjec, 2006: 96).

What is ultimately revealed through this arrested movement, through the moment when running is transformed into stationary data, is the uncertain supposition - of both the self and of self-analysis - that fuels the contemporary moment. The images of the self produced by the tracking application, a spectral self, a self in process and a self in translation, only accrue meaning with their constant repetition. But this same repetition reveals the very falsity of the whole self as, through its proliferation and automated production, the data of self-tracking is a form of writing the self: an inscription and an attempt to exert control on the self in order to create a narrative map towards a different future and a different person that will necessarily never exist. Anxiety emerges in this writing because of both the desire to move towards that future and the impediment to this movement.

\section{Conclusion: "There is No Auto-Analysis"}

In Lacan's understanding of anxiety, inhibition is most clearly about the halting of movement but impediment is a more complex form of blockage (Lacan, 2014: 10). For Lacan, impediment draws its force not from simply stopping the subject; rather it works as a type of ensnarement where "it implies the relationship between one dimension and something that comes to interfere with it and which, in what interests us, impedes not the function, a term of reference, not movement, which is rendered difficult, but truly and verily the subject" (2014: 10). Impediment's power is that it exists as a threshold with- 
held - the subject is arrested between possibilities, between one dimension and something else - and the subject is caught within itself. Just as anxiety presents itself as the cut, as the space between furrowed lips, and as the possibility of attaining the real, impediment reveals itself as a similarly liminal space.

In the case of the obsessive patient, for example, Lacan notes that impediment produces anxiety precisely at the level where the subject is uncertain about the meaning of an act, where the object of desire is unclear and in-between different registers, and where, "He didn't know it was that, and this is why, at the level of the point at which he can't impede himself, he lets go, namely, the to and fro of the signifier that posits and effaces by turns" (2014: 319). As desire moves the obsessive subject forward, he becomes anxious just as he cannot stop himself and he gives himself over to the infinite chain of discourse; he gives himself over to writing, to inscription, to the construction of an imagined Other. As a reminder that the signifier is itself a trace of the lost remainder of the whole self that drives desire forward, the obsessive's relationship to impediment and anxiety reveals how automated self-tracking fuels an insatiable slide into anxiety. As we work to separate an idealized digital self from our selves in the name of auto-analysis - that is, as we look for the cut, or the distance that would allow us access to our true selves - we are left chasing an uncertain object of desire that is, again as Lacan has reminded us, that very self we are fleeing from.

Fantasy steps in here as our guiding principle as, in these moments of anxiety, we look for a plane of consistency, a space of stability to cover our uncertainty. ${ }^{16}$ In this way, the rise of automated self-tracking gestures to something far beyond our own individual anxieties; it gestures to a collective fantasy, to an emerging aesthetic and logic of the present that is part of the larger structure of feeling of the present. In this way, thinking through the prevailing mood for self-tracking can "provide a way to articulate the shaping and structuring effect of historical context on our affective attachments" (Flatley, 2008: 18). That is, the mood of self-tracking can give us a larger sense of how the structure of communicative capitalism, animated by Jodi Dean in her work Blog Theory (2010b), best illustrates our psychic experience of the ongoing present situation. As an envelope that holds the subject in place despite ceding them a sense of political agency and mobility, communicative capitalism is, for Dean, the "materialization of democratic ideals in the contemporary information and

\footnotetext{
${ }^{16}$ Renata Salecl makes clear that fantasy emerges as a way to make sense of, and assuage, our anxieties, explaining that, "Fantasy is a way for the subject to cover up the lack of by creating a scenario, a story that gives him or her consistency. However, fantasy also helps prevent the emergence of anxiety" (Salecl, 2004: 14).
} 
entertainment networks necessary for globalized neoliberalism" (Dean, 2010a: 21). This materialization relies explicitly on the circulation of affect to ensure the subject's repeated participation and engagement. Building upon Lacan's theory of drives, Dean sees this present form of capitalism as one that thrives "not because of unceasing or insatiable desires but in and as the repetitive intensity of drive" (2010a: 30). It is through habituation, through the the repetition and ongoing participation of the subject in the capitalist sphree, that they come to intuit their own place within this network. Even as a model of online participation and communication, Dean most clearly gets to the heart of our fantasy of participation and communication in everyday life by articulating the excessive, and modulated, repetition that keeps a subject attached to modes of being and that propels our participation in the present. As she explains:

"Insofar as affect as a movement designates a doubling of an image, utterance, perception, or sound into itself and something else, we can account for the affective discharge or reflexivized communication. The additive dimension of communication for its own sake designates an excess. This excess isn't a new meaning or perspective. It doesn't refer to a new content. It is rather the intensity accrued from the repetition, the excitement or thrill of more. In the reflexive doubling of communication, the enjoyment attached to communication for its own sake displaces intention, content, and meaning. The something extra in repetition is enjoyment, the enjoyment that captures us in drive, and the enjoyment communicative capitalism expropriates." (Dean, 2010a: 39)

Dean draws out the doubling of affect and its parallelism with the doubled object of communication, the image, utterance, perception or sound, where this mirroring is established as the communicative object is repeated, forwarded, passed along through the network. While she is obviously imagining a more literal doubling of the object in online communication - the forwarded image of, say, a cute cat is doubled not just as affect in the subject and as information on the screen, but also as information received and transmitted out - the excessive that ensnares the subject in the loops and ebbs, and anxieties and pleasures, of online forwarding is not unique to one structure of communication. That is, this excessive doubling is mirrored in the self-tracking application's doubling of the self: at once subject and object, satellite and body, experience and data.

And the fantasy of self-tracking is that it can both end, and maintain, this doubling. Self-tracking in this mode of anxiety is an affective tool for judgment 
and a mode of evaluating the self; it is a distancing aestheticized in the quantified numbers and satellite views of a self. In this distancing, self-tracking presents itself as an automated fantasy Other, where, just as the infant enthralled by their image in the mirror looks over their shoulder to confirm this image with the Other, automated tracking is a form of affective looping where this writing works by "summoning up a companion in the imagination in order to feel the pressure of the other's gaze" (Dean, 2010b: 50). The affective force here, between the self as writer and the imagined and inscribed self as object, is transformed into an automated relationship that only furthers an appearance of objectification and, thus, operates as the anxious push that moves the self away from the subject in order to gain the critical distance necessary to pass judgment. To this end, the act of self-tracking mirrors the act of faltering online communication and, in writing the self through automation it opens up to jouissance and to a specific hope for erasure of the self. There is, as Eugenie Brinkema makes clear, a masochism at work in the reflexive pronoun, in the myself of ourselves:

"A special form of masochism hinges on the problem of a reflexive pronoun - in the movement from I like to be hurt to I like to hurt myself, lost is the logic of intersubjective desire (the implied "by you" of masochism proper), and gained is the signifier that represents me to the statement (my own "myself"). In this movement, a supplement appears: the doubled I/myself found only in the second instance. Agent of desire in iteration one becomes agent of desiring annihilation in iteration two, but, significantly, what is effected in the second sentence is a split - the gashing cut of the diagonal slash that forever holds apart I/myself." (Brinkema, 2009: 131)

This masochism, as a type of desire to annihilate the self, is the masochism of self-help books and of therapeutic discourses; it is the masochism of living in and through the neoliberal present. ${ }^{17}$ This is very much the initial desire, the first affective push that produces our need to self-track. But when this desire becomes automated - when the writing writes itself, when the journal becomes a sensor, and when the Other is replaced by the split my/self - desire is transformed into jouissance. There is no end to the chain of desire that could be quelled by reaching an ideal imagined object and we are all transformed into obsessives. Unable to stop ourselves from this automated writing, the desire to

\footnotetext{
17 This form of masochism is perhaps best understood as part of larger projects to create narratives of self-reliance that have become a means for living through, and coping with, our contemporary neoliberal moment. For a clear description of the rise of these narratives of the self, see da Silva (2014).
} 
control the self is transformed into a habitual loop of jouissance; we no longer know what object it is we are pursuing, and we are left pursuing our own desire, we are left doubled.

Repetition becomes essential to our means of self-tracking precisely because, as Dean argues, "The blockage or stuckness of anxiety, then, is at the same time the repetitive, circular movement of drive" (2010b: 118). Like the obsessive whose own impediment transforms anxiety into the infinite chain of writing and language, or our own desire to self track that cannot impede this same slide, Dean reveals Lacan's larger claim that anxiety is at the centre of the movement between jouissance and desire. ${ }^{18}$ That is, the desire that sets us forth in our attempts at self-tracking - a desire to know our true selves, a desire to become our idealized and perfect whole selves - is very quickly transformed into the jouissance that drives us towards our unreachable objects of desire, our objet petit $a$. Where we imagine we are in control of this digital self, automated tracking reveals it to be an insatiable loop, a never-to-be-completed mode of inscribing the self that necessarily inserts us back into the infinite chain of the signifier. Without an end in sight, our pleasure is infinitely impeded and we are left chasing ourselves in perpetuity.

This, then, drops us right back into the free-fall. As Steyerl has made clear, in the moment of falling, "you will probably feel as if you are floating - or not even moving at all” (Steyerl, 2011). The impediment of anxiety, the stuckness of our uncertainty blocks the hopeful move towards an idealized self and we, the subject-on-the-screen and the subject-in-the-flesh, end up ensnared together, caught in a type of free-fall. When we are faced with both an uncertain grounding and uncertain self, when the aesthetic of self-tracking and the anxiety of auto-analysis meet headlong, the sensation of falling becomes equally uncertain because "Falling is relational - if there's nothing to fall towards, you may not even be aware that you're falling" (Steyerl, 2011). Here the subject and object, the runner and its data, the body and the satellite, the breather and their anxieties, are caught falling together and, left with no possibility of distancing one from the other, it becomes impossible to separate one from the other. Caught in the loops of automated tracking we are revealed to be our own objects of desire and our own anxious objects.

${ }^{18}$ See Lacan, 2014: 320. 


\section{References}

Blackwell, L. (2014). Affect and Automatic: Towards an Analytics of Experimentation. Subjectivity, 7(4): 362-384.

Brinkema, E. (2009). To Cut, to Split, to Touch, to Eat, as of a Body or a Text: Secretary and Dans ma peau. Angelaki: Journal of Theoretical Humanities, 14(3): 131-145.

Chun, W. H. K. (2016). Big Data as Drama. ELH, 83(2): 363-382.

Clark, D. \& Aaron, T. 2011). Cognitive Therapy of Anxiety Disorders: Science and Practice. New York: Guilford Press.

Copjec, J. (2006). May '68: The Emotional Month. In Žižek, S. (ed.), Lacan: The Silent Partner (pp. 90-114). London: Verso Books

Da Silva, J. (2013). Coming Up Short: Working-Class Adulthood in an Age of Uncertainty. Cambridge: Oxford University Press.

Dean, J. (2010a). Affective Networks. MediaTropes, 2(2): 19-44.

Dean, J. (2010b). Blog Theory: Feedback and Capture in the Circuits of Drive. Hoboken: John Wiley \& Sons.

De Certeau, M. (1984). The Practice of Everyday Life. Berkeley: University of California Press.

Flatley, J. (2009). Affective Mapping: Melancholia and the Politics of Modernism. Cambridge: Harvard University Press.

Foucault, M. (1997). Ethics: Subjectivity and Truth: the Essential Works of Michael Foucault, 1954-1 1984. (ed. Rabinow, P.). London: Penguin.

Freud, S. (1895). On the Grounds for Detaching a Particular Syndrome from Neurasthenia under the Description 'Anxiety Neurosis'. The Standard Edition of the Complete Psychological Works of Sigmund Freud, Volume III (18931899) (pp. 85-115). London: Hogarth Press

Freud, S. (1926). Inhibitions, Symptoms and Anxiety. Cambridge: Oxford University Press.

Freud, S. (1936). The Problem of Anxiety. New York: The Psychoanalytic Quarterly Press 
Galloway, A. (2006). Gaming: Essays on Algorithmic Culture. Minnesota: University of Minnesota Press.

Johnstone, A. (2002). The Forced Choice Of Enjoyment: Jouissance between Expectation and Actualization. Accessed 20. 07. 2016. URL: http://www. lacan.com/forced.htm

Lacan, J. (1992). The Ethics of Psychoanalysis: The Seminar of Jacques Lacan, Book VII. London: Routledge.

Lacan, J. (1998). Encore: The Seminar of Jacques Lacan, Book XX. New York: W.W. Norton and Company.

Lacan, J. (2014). Anxiety: The Seminar of Jacques Lacan, Book X. Cambridge: Polity Press.

Morozov, E. (2013). To Save Everything, Click Here. New York: Public Affairs.

Salecl, R. (2004). On Anxiety. London: Routledge.

Shouse, E. (2005). Feeling, Emotion, Affect. M/C journal, 8(6): 24-30 "Spire -The Mindfulness and Activity Tracker”. Retrieved from: https://spire.io/

Steyerl, H. (2011). In Free Fall: A Thought Experiment on Visual Perspective. Accessed 22. 07. 2016. URL: http://www.e-flux.com/journal/in-free-fall-athought-experiment-on-vertical-perspective/

Thrift, N. (2004). Intensities of Feeling: Towards a Spatial Politics of Affect. Geografiska Annaler: Series B, Human Geography, 86(1): 57-78.

"What is Nike Fuel?". Retrieved from: https://secure-nikeplus.nike.com/plus/ what_is_fuel/

Whitson, J. (2014). Foucault's Fitbit: Governance and Gamification. In Waltz, S. P. \& Deterding, S. (eds.), The Gameful World: Appproaches, Issues, Applications (pp. 339-358). Cambridge: MIT Press.

Wolf, G. (2010). The Data-Driven Life. Accessed 21. 07. 2016. URL: http:// www.nytimes.com/2010/05/02/magazine/02self-measurement-t.html 